\title{
Public health, beneficence and cosmopolitan justice
}

\author{
L Horn, MB ChB, DTM\&H, DCH(SA), MPhil (Applied Ethics), Diploma: International Research Ethics, PhD \\ Centre for Applied Ethics, Department of Philosophy and Division for Research Development, Stellenbosch University, South Africa
}

Corresponding author: L Horn (Ihorn@sun.ac.za)

\begin{abstract}
This article proposes that, in line with moral-cosmopolitan theorists, affluent nations have an obligation, founded in justice and not merely altruism or beneficence, to share the responsibility of the burden of public health implementation in low-income contexts. The current Ebola epidemic highlights the fact that countries with under-developed health systems and limited resources cannot cope with a significant and sudden health threat. The link between burden of disease, adverse factors in the social environment and poverty is well established and confirmed by the 2008 World Health Organization (WHO)'s Social Determinants of Health Commission report. Well-resourced nations generally consider that they have some humanitarian obligation to assist where possible, but this obligation is limited. The following questions are considered: Is reliance on the principle of beneficence to address the global disparities in the social determinants of health and life expectancy at birth good enough? Do well-resourced nations have some obligation from justice, which is stronger than from beneficence, and which cannot be as easily cast aside or diminished, to address these issues? In a globalised world, shaped by centuries of historical injustice and where first-world economies are now so intertwined and reliant on third-world labour, beneficence is not a strong enough principle on which to base an obligation to achieve the WHO vision of 'health equity through action on the social determinants of health'.
\end{abstract}

S Afr J BL 2015:8(2):30-33. DOI:10.7196/SAJBL.436

It is proposed that, in line with moral-cosmopolitan theorists, affluent nations have an obligation, founded in justice and not merely altruism or beneficence, to share the responsibility of the burden of public health implementation in low-income contexts. This view is controversial with little agreement in recent debate. The current ebola epidemic highlights the fact that countries with under-developed health systems and limited resources cannot cope with a significant and sudden health threat. The Western world has come under severe criticism for a delayed and inadequate response, only taking the situation seriously when the threat of the epidemic came close to home, and a US doctor who had been working in West Africa returned to New York and rode the subway before becoming symptomatic. ${ }^{[1]}$ Responding to the Ebola outbreak, it has been argued that high-income countries have an obligation to address this, first motivated from beneficence, and then from justice. ${ }^{[2]}$

A comment on the results of the Wellcome Trust funded INDEPTH network project, suggested that a reason that West African countries have been so badly affected by Ebola, is that because of relatively low HIV incidence, they have not benefited from health systems development linked to the HIV epidemic. ${ }^{[3,4]}$ The HIV epidemic resulted in programmes such as the US President's Emergency Fund for AIDS Relief (PEPFAR) and the Bill and Melinda Gates Foundation providing financial resources to bolster local health systems to curb the HIV epidemic. HIV mortality rates are dropping in countries benefiting from these resources and antiretroviral therapy (ART) treatment programmes, where these have become widely available. ${ }^{[5]}$ However, health systems in the three impoverished countries that have borne the brunt of the recent Ebola epidemic, Liberia, Sierra Leone and Guinea, have buckled under the pressure. Their prolonged civil wars have aggravated the situation and undermined their ability to repair and further develop effective public health infrastructure.

Senegal was one West African country that successfully curtailed the Ebola epidemic and prevented Ebola from spreading. Senegal confirmed one case of Ebola on the 29 August 2014, and immediately launched a nationwide well-coordinated public health campaign using mobile phones and text messages (SMS) to spread information and prevention messages. The WHO reported that an important reason for Senegal's effective response was because the infrastructure was already in place in the form of the Mobile-Diabetes (mDiabetes) campaign that was launched in June 2014. This project is part of a joint global initiative between the WHO and the International Telecommunication Union (ITU), called Be He@lthy Be Mobile, ${ }^{[6]}$ which requires in-country financial and leadership commitment but has significant international partner support. ${ }^{[7]}$

The link between burden of disease, adverse social environment factors and poverty is well established and confirmed by the 2008 WHO's Social Determinants of Health Commission report. ${ }^{[8]}$ This link is also discussed in a book chapter 'The State of Global Health in a Radically Unequal World: Patterns and Prospects, ${ }^{[9]}$ which concludes that 'the success stories cited ... depended on effective and sustained mobilisation of financial and other resources both domestically and internationally. However, apprehension has also been expressed about the future availability of resources to continue these initiatives with one US commentator referring to ARV as a 'ballooning entitlement burden! ${ }^{[9,10]}$

The same can be said about the above examples. Parallels have been drawn between Ebola and HIV, two examples of burden of disease prevalent in the developing world that are aggravated by economic disadvantage and require significant financial resources to control. The negative synergistic link between tuberculosis (TB) and diabetes is also an example of a burden-of-disease pair prevalent in the developing world. ${ }^{[11,12]}$

Globalised world economies are extensively linked and interdependent on each other, even if nationalism is seen to be an increasingly important force. However, globalisation has not reduced poverty and global inequality has worsened since the end of the 
cold war. Wealthy countries outsource material production to places where the labour is cheap and safety and environmental hazards rules are lax. Multinational companies based in well-resourced nations also play a role in maintaining power imbalances between rich and poor nations. ${ }^{[13]}$ These power imbalances perpetuate the 'systematic patterns of disadvantage' that result in the perpetuation of inequalities in the social determinants of health, or the'dimensions of well-being' identified as essential for adequate public health. ${ }^{[14]}$

\section{Beneficence versus justice in the context of public health}

Successes over the last decade regarding HIV have largely been driven by financial support by Western nations, particularly the USA. Commentators generally agree that their motivation is primarily humanitarian, with efforts based on the principle of beneficence or altruism. Much funding, e.g. for HIV research, has come from charitable foundations like the Bill and Melinda Gates Foundation. Beauchamp and Childress ${ }^{[15]}$ describe beneficence as a positive duty with incomplete obligation. It is also an obligation that can be fulfilled with some degree of partiality. 'Virtually everyone agrees that all persons are obligated to act in certain circumstances in the interests of their children, friends and other special parties but general beneficence is more controversial'. They further state that the idea that we have 'the same impartial obligations to persons we do not know as to our own family ... is also perilous because this unrealistic and alien standard may divert attention from our obligations to those to whom we are close or indebted, and to whom our responsibilities are clear rather than clouded'. Singer ${ }^{[16]}$ has also discussed the concept of beneficence within the context of famine and poverty and put some limits on it. $\mathrm{He}$ differentiates from 'doing good' and 'preventing harm' and argues that if we can prevent something bad from happening, no matter where in the world, 'without thereby sacrificing anything of comparable moral importance, we ought, morally to do it'. Therefore we have a humanitarian obligation to assist where we can, but this obligation is limited. Questions to consider are: Is reliance on the principle of beneficence to address the global disparities in the social determinants of health and life expectancy at birth (LEB) good enough? Do wellresourced nations have some obligation from justice, which is stronger than an obligation from beneficence, and which cannot be as easily cast aside or diminished, to address these issues? For example, even when changing economic or political circumstances come into prominent focus at a national level and shift perceptions of what counts as things of 'comparable moral importance'.

\section{Cosmopolitan justice and public health ${ }^{[17]}$}

Discussions of distributive justice do seem to be based on the assumption that the principles expounded belong in a 'bounded society' and that their application is 'a primary task of states'.[18] That is, obligations determined by principles of distributive justice are confined to within the borders of states, and do not apply globally. However, much argument and debate counteracts this assumption and argues that there are cosmopolitan principles of justice that apply globally and place cross-border obligations and duties on states. ${ }^{[19,}{ }^{20]}$ 'Cosmopolitanism' can be applied to many things such as 'schemes of world political order and conceptions of individual cultural identity', hence Beitz refers specifically to 'moral cosmopolitanism' when using the term in the context of a discussion of global justice. ${ }^{[17,21]}$
'Moral cosmopolitanism' is an approach to issues of global justice that has many different versions and continues to be the focus and subject of much current debate. However, three key principles common to most cosmopolitan approaches have been proposed:

- The value of individuals (no matter where they live in the world)

- The equality of individuals (no matter where they live in the world)

- Obligations of duty that apply to everyone, not just to my fellow citizens or community, my own ethnic group or religious community. ${ }^{[17,19]}$

These principles are broadly reflected by the WHO Social Determinants of Health report, ${ }^{[7]}$ even if not explicitly stated. People in a modern liberal democracy generally accept the first two principles. The third principle is more controversial. Therefore, from a perspective of cosmopolitan justice, public health problems, especially those caused by poverty and 'entrenched patterns of systematic disadvantage ${ }^{[114]}$ in poor countries, are not only the responsibility of the government or institutions of that country but are also, under an obligation of justice, the responsibility of affluent nations.

'Three elements are shared by all cosmopolitan positions. First, individualism: the ultimate units of concern are human beings, or persons - rather than, say, family lines, tribes, ethnic, cultural, or religious communities, nations or states. The latter may be units of concern only indirectly, in virtue of their individual members or citizens. Second, universality: the status of ultimate unit of concern attaches to every living human being equally - not merely to some sub-set, such as men, aristocrats, Aryans, whites or Muslims. Third, generality: this special status has global force. Persons are ultimate units of concern for everyone - not only for their compatriots, fellow religionists, or such like. ${ }^{[17,19,22]}$

The world faces numerous urgent global problems that involve matters related to justice ${ }^{[2]]}$ among which inequities in the social determinants of health must rank high.

Beitz's ${ }^{[23]}$ 'Political Theory and International Relations' was one of the first major contributions to the development of a concept of cosmopolitan justice. He produces two central arguments against Rawls, ${ }^{[24]}$ one of the most influential political philosophers of the twentieth century. Beitz argues that Rawls' assumption that states are self-sufficient and operate independently is false. Globally, economies are so interdependent that this creates a moral obligation of distributive justice. Second, distribution of the world's natural resources is as arbitrary as the distribution of 'talents' when considered from the standpoint of a global 'original position'. Thus, Beitz argues, a global version of Rawls' 'difference principle' is required. Rawl's difference principle states in essence that the basic goods of society should be distributed equally unless an unequal distribution is to the advantage of the 'least advantaged group'. The purpose of this principle is to compensate for life's lottery, which sees some being born into severe poverty with limited talents and others getting the best start in life (natural talent and intellect or affluent home circumstances), through no effort of their own. He proposes a global resource redistribution principle which would mean that countries that have fared very well in the distribution of natural resources must compensate those who have fared poorly; namely, this principle would function at an international level in the same way as the difference principle functions at a domestic level. ${ }^{[23]}$

Many scholars have joined Beitz in supporting and expanding these arguments. Pogge $\mathrm{e}^{[20,22,25]}$ argues that affluent societies have a 
negative duty not to harm those in poor societies and that for many reasons, particularly colonialism and exploitative global economic policies; they are responsible for having done just that. Pogge ${ }^{[25]}$ sets out an argument based in part on Locke's ${ }^{[26}$ 'inalienable right to a portion of the world's resources or an adequate equivalent' in support of a 'small change in international property rights' which he calls a Global Resource Dividend, specifically for poverty reduction. At $1 \%$ of global social product this would raise an amount 86 times more than what well-off countries currently spend on 'basic social services' in low-income countries. ${ }^{[25]}$

While these scholars of cosmopolitan justice may differ in many respects they all hold in common the three identified core principles. Some political theorists or philosophers in social justice do not support the third principle, namely, that the duty of justice owed to fellow citizens is no greater than that owed to individuals living in far corners of the world. Miller ${ }^{[27]}$ addresses this issue in 'National Responsibility and Global Justice'. He states that many of us have two conflicting intuitions. The first is that the enormous differences in per capita income, burden of disease and life expectancy between the first world and developing-world countries is unjust. The second is that in matters of justice national responsibility must take precedence and hence such inequality is inevitable. He proposes a compromise between cosmopolitanism and national justice but argues that 'we should treat national responsibility for outcomes as the norm rather than the exception. ${ }^{\text {[27] }}$ Ghana and Malaysia, who obtained independence from Britain in 1975, are cited to illustrate that poor domestic governance and choices have resulted in Malaysia being far better-off than Ghana. ${ }^{[27]}$ Poor governance and corrupt governance adversely affect the social determinants of health in many developing-world countries; and the sorry state of their populations' health status would not be such if their governments were more interested in service than power, which Pogge concedes. ${ }^{[25]}$ However, those in government often do not suffer but rather those living in impoverished or vulnerable communities with little influence over national policy. Pogge ${ }^{[25]}$ makes the point that powerful countries often shape the regimes in weak countries because they recognise such leaders, and do not question their power or authority to sell their countries' natural resources, borrow internationally and then entrench patterns of power, elitism and cronyism in their countries. He argues that there is a negative synergism between global economics and unjust national policies and governments and that the effect of this interaction is multiplicative.

I therefore disagree with Miller who believes that collective responsibility operates in both democracies and authoritarian states. The HIV epidemic in South Africa (SA) is a case in point. SA has one of the worst HIV epidemics globally with many contributing factors. The HIV denialism by the then-president (Thabo Mbeki) and Minister of Health (Manto Tshabalala-Msimang) contributed to this situation, but the colonial and apartheid past also contributed to the underlying structures that allowed the epidemic to spiral out of control. The historically disadvantaged and most vulnerable members of the population bore the brunt of this epidemic. Many in SA would agree that it was only with international intervention, such as the PEPFAR programme, that the situation started to turn around.

Since 2008 the world has been affected by a global recession and the arguments of those supporting a cosmopolitan approach to social justice have become less attractive. Western democracies tend to turn inwards and focus more on domestic priorities rather than the public health concerns of developing countries. If the principle of beneficence underpins the development of, and support for, global health programmes - these can more easily be set aside. For example, the dramatic budget cut of USD214 million that President Obama has made to HIV funding programmes in 2013, which is having a negative impact on successful PEPFAR - funded programmes in SA. ${ }^{[28-31]}$

\section{Conclusion}

The link between public health and social justice should be closely established and an essentialist conception of social justice can provide a foundation for public health programmes. ${ }^{[32]}$ In agreement with cosmopolitan theorists | believe well-resourced countries have an obligation founded on justice, not merely on altruism or beneficence, to assist developing-world countries to recognise and accept the demands such an approach to public health would make. Furthermore these countries must accept some co-responsibility and accountability, based on justice, in meeting these demands. I do not suggest that well-resourced countries should accept this entire burden, or that developing-world countries do not have a major role to play in developing and funding appropriate public health projects in their own country. Instead I argue for the principle that beneficence alone is not good enough as a motivating force for support of public health in developing-world countries. This would mean some acceptance of the notion of justice within the arena of global public health as a point of departure. It may require, as Pogge has suggested, major reordering of global economic systems and an acknowledgement that our world and humanity is far more interconnected, historically and currently, than we sometimes like to believe. We are a long way off reaching any form of agreement on what shape justice, as a global health principle, should take.

This paper focuses on global responsibility for the social determinants of health worldwide, and the justice imperative that involves well-resourced states in the development and support of public health programmes that extend beyond national borders. Public health, which is concerned with the health of populations and communities rather than individuals, and delivered mainly by governments and other organisations rather than individual healthcare service providers, is where these obligations must be addressed and where it can make the biggest positive impact. Nonetheless, the borders between public health and health service delivery are often blurred and there may be little purpose in attempting to separate out the two domains, because the same underlying negative social determinants of health promote illness that require the delivery of therapeutic health services at an individual level. Therefore, these arguments may also be appropriate for health service delivery in certain contexts, e.g. the provision of ART and TB treatment in countries, such as SA, experiencing overwhelming epidemics. This may similarly apply to African and Asian countries with severe malaria epidemics and more recently, the Ebola epidemic.

\section{References}

1. Gonsalves G, Statley P. Panic, paranoia and public health - the AIDS epidemic's lessons for Ebola. N Engl J Med 2014;371(25)2348-2349. [http://dx.doi.org/10. 1056NEJMp1413425]

2. Rid A, Emmanuel EJ. Why should high-income countries help combat Ebola? JAMA 2014;312(13):1297-1298. [http://dx.doi.org/10.1001/jama.2014.12869] 
3. Boseley S. Mail \& Guardian. October 31 to November 6 2014:19.

4. Boerma T. Moving towards better cause of death registration in Africa and Asia. Glob Health Action 2014;10(7):25931 [http://dx.doi.org/10.3402/gha.v7.25931]

5. Streatfield PK, Khan WA, Bhuiya A, et al. HIV/AIDS-related mortality in Africa and Asia: Evidence from INDEPTH health and demographic surveillance system sites. Glob Health Action 2014;10(7):25370 [http://dx.doi.org/10.3402/gha.v7.25370]

6. International Telecommunications Union (ITU). Be He@lthy. Be Mobile. Geneva: ITU, 2014. http://www.itu.int/en/ITU-D/ICT--Applications/eHEALTH/Be_healthy/ Pages/Countries.aspx (accessed 24 November 2014).

7. World Health Organization. Government of Senegal boosts awareness through SMS campaign. Geneva: World Health Organisation, 2014. http://www.who.int/ features/2014/senegal-ebola-sms/en/ (accessed 20 November 2014).

8. World Health Organization. Commission on Social Determinants of Health Report 2008. Closing the Gap in a Generation: Health Equity through Action. Geneva: World Health Organisation, 2008 http://www.who.int/social_determinants/ thecommission/finalreport/en/ (accessed 26 February 2014).

9. Labonté $\mathrm{R}$, Schrecker T. The state of global health in a radically unequal world: Patterns and prospects. In: Benatar S, Brock G, eds. Global Health and Global Health Ethics. Cambridge: Cambridge University Press, 2011:24-36.

10. Over M. Prevention failure: The ballooning entitlement burden of US global AIDS treatment spending and what to do about it. Center for Global Development Working Paper 144, 2008

11. Times Live. New Global Health Threat. Johannesburg: Times Live, 31 October 2014 http://www.timeslive.co.za/thetimes/2014/10/31/new-global-health-threat (accessed 20 November2014)

12. International Diabetes Federation. Diabetes and Tubersulosis. Brussels: International Diabetes Federation, 2014. http://www.idf.org/print/ diabetesatlas/5e/diabetes-and-tubersulosis (accessed 7November2014).

13. Birn AE. Addressing the societal determinants of health: The key global health imperative of our times. In: Benatar S, Brock G, eds. Global Health and Global Health Ethics. Cambridge: Cambridge University Press, 2011:37-52.

14. Powers M, Faden R. Social Justice: The Moral Foundations of Public Health and Health Policy. Oxford: Oxford University Press, 2006:9.

15. Beauchamp TL, Childress JF. Principles of Biomedical Ethics. Fifth ed. New York: Oxford University Press, 2001:169.

16. Singer P. Famine, affluence and morality. Philosophy \& Public Affairs 1972;1 (3):229-243
17. Horn LM. Virtue ethics in the development of a framework for public health. 2010. $\mathrm{PhD}$ thesis. Stellenbosch: Stellenbosch University, 2010:22-30. http://scholar.sun. ac.za/handle/10019.1/5418.

18. O'Neill O. Bounded and cosmopolitan justice. Review of International Studies 2000;26(5):45-60. [http://dx.doi.org/10.1017/S0260210500000450]

19. Caney S. Justice Beyond Borders. Oxford: Oxford University Press, 2005:4.

20. Pogge TW. World Poverty and Human Rights: Cosmopolitan Responsibilities and Reforms. Cambridge: Polity Press, 2002:7-123.

21. Beitz CR. Cosmopolitanism and global justice. In: Current Debates in Global Justice. Netherlands: Springer, 2005:11-27. [http://dx.doi.org/10.1007/1-40203847-X_2]

22. Pogge TW. Cosmopolitanism and Sovereignty. In: Political Restructuring in Europe: Ethical Perspectives, Brown C, eds. London: Routledge, 1994:89-122.

23. Beitz CR. Justice and international relations. Philosophy \& Public Affairs 1975;4(4):360-389.

24. Rawls J. A Theory of Justice. USA: Oxford University Press, 1999

25. Pogge TW. Real world justice. The Journal of Ethics 2005;9:29-53.

26. Locke J. Two treatises of civil government (1690). In: Wootten D, ed. Locke, Political Writings. London: Penguin, 1993:29.

27. Miller D. National responsibility and global justice. Critical Review of International Social and Political Philosophy 2008:11(4):383-399.

28. USA.gov. The United States President's Emergency Plan for Aids Relief Washington: USA.gov, 2014 http://www.pepfar.gov/ (accessed 26 February 2014).

29. United States Diplomatic Mission to South Africa. 10 Years of PEPFAR:The Power of Partnership. Washington: United States Diplomatic Mission to South Africa, 2014. http://southafrica.usembassy.gov/pepfar.html (accessed 26 February 2014).

30. Aids Health Foundation. South Africa: 1000 protest U.S AIDS funding cuts. Los Angeles: Aids Health Foundation, 18 March 2013. http://www.aidshealth.org/ archives/1591 (accessed 25 February, 2014).

31. Aids Health Foundation. Obama budget decimates global aids funding. Los Angeles: Aids Health Foundation, 2013. http://www.aidshealth.org/archives/ news/obama-budget-decimates-global-aids-funding (accessed 25 February 2014).

32. Horn LM. Public health and social justice: Forging the links. S Afr J BL 2015;8(2):2629. [http://dx.doi.org/10/7196/SAJBL.437] 